\title{
More than additive effects on liver triglyceride accumulation by combinations of steatotic and non-steatotic pesticides in HepaRG cells
}

\author{
Alexandra Lasch ${ }^{1} \cdot$ Philip Marx-Stoelting ${ }^{2} \cdot$ Albert Braeuning $^{1}\left[\right.$ D Dajana Lichtenstein ${ }^{1}$
}

Received: 17 December 2020 / Accepted: 28 January 2021 / Published online: 11 February 2021

(c) The Author(s) 2021

\begin{abstract}
The liver is constantly exposed to mixtures of hepatotoxic compounds, such as food contaminants and pesticides. Dose addition is regularly assumed for mixtures in risk assessment, which however might not be sufficiently protective in case of synergistic effects. Especially the prediction of combination effects of substances which do not share a common adverse outcome (AO) might be problematic. In this study, the focus was on the endpoint liver triglyceride accumulation in vitro, an indicator of hepatic fatty acid changes. The hepatotoxic compounds difenoconazole, propiconazole and tebuconazole were chosen which cause hepatic fatty acid changes in vivo, whereas fludioxonil was chosen as a hepatotoxic substance not causing fatty acid changes. Triglyceride accumulation was analyzed for combinations of steatotic and non-steatotic pesticides in human HepaRG hepatocarcinoma cells. Investigations revealed a potentiation of triglyceride accumulation by mixtures of the steatotic compounds with the non-steatotic fludioxonil, as compared to the single compounds. Mathematical modeling of combination effects indicated more than additive effects for the tested combinations if the method by Chou was applied, and a decrease in $\mathrm{EC}_{50}$ values of the steatotic compounds when applied in mixtures. Use of an adverse outcome pathway (AOP)-driven testing strategy for liver steatosis showed interactions of the test compounds with the nuclear receptors AHR, CAR and PXR, as well as a downregulation of ACOX2. An ACOX2-dependent mechanism underlying the observed mixture effect could not be verified using a siRNA approach. By contrast, a toxicokinetic interaction was identified including an inhibition of the metabolic enzyme CYP3A4 by fludioxonil and a decreased metabolic conversion of the CYP3A4 substrate difenoconazole when used in mixture experiments. In conclusion, an interaction by a steatotic and a non-steatotic compound at the toxicokinetic level on the endpoint triglyceride accumulation in vitro was described.
\end{abstract}

Keywords Mixtures $\cdot$ Adverse outcome pathway $\cdot$ Liver steatosis $\cdot$ Nuclear receptor activation $\cdot$ Pesticides

$\begin{array}{ll}\text { Abbreviations } \\ \text { AHR } & \text { Aryl hydrocarbon receptor } \\ \text { AO } & \text { Adverse outcome } \\ \text { AOP } & \text { Adverse outcome pathway } \\ \text { CA } & \text { Concentration addition concept } \\ \text { CAG } & \text { Cumulative assessment group } \\ \text { CAR } & \text { Constitutive androstane receptor } \\ \text { CI } & \text { Combination index }\end{array}$

Albert Braeuning

Albert.Braeuning@bfr.bund.de

1 Department of Food Safety, German Federal Institute for Risk Assessment, Max-Dohrn-Straße 8-10, 10589 Berlin, Germany

2 Department of Pesticides Safety, German Federal Institute for Risk Assessment, Max-Dohrn-Straße 8-10, 10589 Berlin, Germany

$\begin{array}{ll}\text { EC }_{50} & \text { Half-maximal effective concentration } \\ \text { ER } & \text { Estrogen receptor } \\ \text { EROD } & \text { Ethoxyresorufin- } O \text {-deethylase } \\ \text { DIF } & \text { Difenoconazole } \\ \text { FDO } & \text { Fludioxonil } \\ \text { FXR } & \text { Farnesoid-X-receptor } \\ \text { GR } & \text { Glucocorticoid receptor } \\ \text { IA } & \text { Independent action concept } \\ \text { KE } & \text { Key event } \\ \text { KTC } & \text { Ketoconazole } \\ \text { LXR } & \text { Liver-X-receptor } \\ \text { MDR } & \text { Model deviation ratio } \\ \text { MIE } & \text { Molecular initiating event } \\ \text { NR } & \text { Nuclear receptor } \\ \text { PPAR } & \text { Peroxisome proliferator-activated receptor } \\ \text { PPC } & \text { Propiconazole } \\ \text { PXR } & \text { Pregnane-X-receptor }\end{array}$


RAR Retinoic acid receptor

RXR Retinoid X receptor

TA Theoretical additivity method

TBC Tebuconazole

\section{Introduction}

The constant exposure of consumers to mixtures of chemicals is of concern for risk assessment as they could, in principle, cause toxic effects in humans different from the effects of individual compounds. Risk assessment is mostly done for single compounds and thus might not accurately reflect the actual risks resulting from multiple exposures. Biological effects that may occur with a chemical mixture can be classified into additive, antagonistic or synergistic effects (ECHA 2017; More et al. 2019; OECD 2018; Rotter et al. 2018), whereby especially synergistic effects are of concern to the consumer as the general assumption for risk assessment of mixtures is dose addition. Given the almost infinite number of possible combinations, the appropriate evaluation of the interaction of substances in vitro is an important topic in food toxicology that warrants further research. Essential for the assessment of mixtures is information about the mode of action of the individual substances, as this information may help predicting possible overadditive effects.

Liver steatosis is a widespread disease and has gained more and more attention over the last years (Perumpail et al. 2017). It is characterized by an increased intracellular triglyceride content in hepatocytes. Several factors may participate in the development of steatosis, such as toxicants and drugs (Al-Eryani et al. 2015; Fromenty and Pessayre 1997; Joshi-Barve et al. 2015). Vinken (2015) and Mellor et al. (2016) depicted the mechanism of this toxicological process in an adverse outcome pathway (AOP). AOPs link a molecular initiating event (MIE) with key events (KE) which then lead to an adverse outcome (AO) (Ankley et al. 2010; Villeneuve et al. 2014). Nuclear receptor (NR) activation is named as the molecular initiating event (MIE) in the steatosis AOP. NRs involved in the progression of steatosis are the aryl hydrocarbon receptor (AHR), constitutive androstane receptor (CAR), estrogen receptor (ER), farnesoid-X-recptor (FXR), glucocorticoid receptor (GR), liver-X-receptor (LXR), peroxisome proliferator-activated receptor (PPAR) alpha, pregnane-X-receptor (PXR), retinoic acid receptor (RAR) and retinoid-X-receptor (RXR) (Mellor et al. 2016; Vinken 2015). The interaction of chemical agonists with those receptors leads to several intermediate effects like altered gene expression (MLXIPL, SREBF1, SCD, FASN, $C D 36$ ), increase of fatty acid influx, de novo synthesis of fatty acids, inhibition of respiration and mitochondrial/ microsomal $\beta$-oxidation and finally to liver triglyceride accumulation (Mellor et al. 2016).
Aim of this study was to evaluate if combination effects on liver triglyceride accumulation may occur when substances which do not share the same AO are combined. Therefore, analysis of triglyceride accumulation was performed using combinations of steatotic and non-steatotic substances in the human hepatocarcinoma cell line HepaRG. Previous studies already revealed that HepaRG cells are an appropriate model to study steatosis in vitro (Antherieu et al. 2010; Knebel et al. 2019a; Lasch et al. 2020a; Luckert et al. 2018; Tanner et al. 2018; Tolosa et al. 2016). The following test substances were chosen: fludioxonil (FDO) as a non-steatotic substance, as well as difenoconazole (DIF), propiconazole (PPC) and tebuconazole (TBC) as steatotic substances. Within the cumulative assessment groups (CAG) for pesticides established by the European Food Safety Authority EFSA, FDO is listed as toxic to the liver but not reported to cause hepatic fatty changes. In contrast, the three triazoles DIF, PPC and TBC are described as toxic to the liver and to cause fatty changes in the liver (Nielsen et al. 2012).

\section{Materials and methods}

\section{Chemicals}

Difenoconazole (DIF) (1-[[2-[2-chloro-4-(4-chlorophenoxy) phenyl]-4-methyl-1,3-dioxolan-2-yl]methyl]-1,2,4-triazole) (CAS 119446-68-3; batch: BCBS9001V; purity: $\geq 99 \%$ ) and fludioxonil (FDO) (4-(2,2-difluoro-1,3-benzodioxol-4-yl)$1 H$-pyrrole-3-carbonitrile) (CAS 131341-86-1; batch: BCBV2209; purity: $\geq 99 \%$ ) were obtained from SigmaAldrich (Taufkirchen, Germany). Propiconazole (PPC) (1-[[2-(2,4-dichlorophenyl)-4-propyl-1,3-dioxolan-2-yl] methyl]-1,2,4-triazole) (CAS 60207-90-1; batch:G144536; purity: 99.0\%) and tebuconazole (TBC) (1-(4-chlorophenyl)4,4-dimethyl-3-(1,2,4-triazol-1-ylmethyl)pentan-3-ol) (CAS 107534-96-3; batch: G142375; purity: 99.6\%) were obtained from LGC Standards (Wesel, Germany).

\section{Cultivation of HepaRG and HepG2 cells}

HepaRG cells (Biopredic International, Sant Grégoire, France) were cultivated 4 weeks before they were used for experiments (Gripon et al. 2002): cultivation was divided into two weeks of proliferation and two weeks of differentiation. Cells were seeded in 96-well plates at a density of 9000 cells/well and in 12-well plates at a density of 100,000 cells/well. Proliferation was achieved in William's medium E with $2 \mathrm{mM}$ glutamine (PAN-Biotech, Aidenbach, Germany) 10\% fetal bovine serum (FBS; FBS Good Forte EU approved; PAN-Biotech, Aidenbach, Germany), $100 \mathrm{U} / \mathrm{mL}$ penicillin and $100 \mu \mathrm{g} / \mathrm{mL}$ streptomycin (Capricorn Scientific, Ebsdorfergrund, Germany), 0.05\% 
human insulin (PAN-Biotech, Aidenbach, Germany) and $50 \mu \mathrm{M}$ hydrocortisone-hemisuccinate (Sigma-Aldrich, Taufkirchen, Germany). Differentiation medium consisted of proliferation medium with additional $1.7 \%$ dimethylsulfoxide (DMSO). $48 \mathrm{~h}$ before experiments, medium of differentiated HepaRG cells was changed to induction medium, containing only $2 \% \mathrm{FBS}$ and $0.5 \%$ DMSO.

HepG2 (ECACC, Salisbury, UK), a human hepatocellular carcinoma cell line, was cultivated in Dulbecco's modified Eagle's medium (DMEM; Pan-Biotech, Aidenbach, Germany). DMEM was supplemented with $10 \%$ FBS (FBS Capricorn Scientific, Ebsdorfergrund, Germany) and $100 \mathrm{U} / \mathrm{mL}$ penicillin and $100 \mu \mathrm{g} / \mathrm{mL}$ streptomycin (Capricorn Scientific, Ebsdorfergrund, Germany). By the time cells reached a confluence of $80 \%$, they were passaged or seeded at a density 22,000 cells/well in 96 -well plates. During treatment, the medium contained $0.5 \%$ DMSO. Both cell lines were cultivated at $37{ }^{\circ} \mathrm{C}$ and $5 \% \mathrm{CO}_{2}$ in a humidified atmosphere.

\section{Cell viability test}

The WST-1 assay (Hoffmann-La Roche, Basel, Switzerland) was used for analysis of cytotoxic effect of the test compounds. Cytotoxic effects of test compounds in HepaRG cells were estimated after $72 \mathrm{~h}$ of incubation and in HepG 2 cells after $24 \mathrm{~h}$ of incubation in 96-well format. $10 \mu \mathrm{L}$ WST-1 reagent was added to each well one hour before the end of incubation. Absorbance of WST-1 was measured at $450 \mathrm{~nm}$ together with a reference wavelength of $620 \mathrm{~nm}$ one hour after addition to the cells.

\section{Triglyceride measurement}

AdipoRed reagent (Lonza, Basel, Switzerland) was used to measure the intracellular amount of triglycerides in HepaRG cells after $72 \mathrm{~h}$ of incubation. The assay was performed in 96-well plates with 6 technical replicates for each test concentration. Prior to fluorescence measurement, cells were washed with $200 \mu \mathrm{L}$ phosphate-buffered saline (PBS) and after this, $200 \mu \mathrm{L}$ PBS containing $5 \mu \mathrm{g} /$ $\mathrm{mL}$ Hoechst 33,342 (Thermo Fisher Scientific, Waltham, Massachusetts, USA) was added to each well. At last, $5 \mu \mathrm{L}$ AdipoRed reagent was added. 96-well plates were incubated for additional $10 \mathrm{~min}$ at $37^{\circ} \mathrm{C}$. Measurement of fluorescence was done with an excitation wavelength of $485 \mathrm{~nm}$ and emission at $572 \mathrm{~nm}$ for AdipoRed, and with excitation at $350 \mathrm{~nm}$ and emission at $461 \mathrm{~nm}$ for Hoechst 33,342 . To compensate variations in cell numbers, AdipoRed signals were normalized to Hoechst 33,342 signals.

\section{EROD activity}

CYP1A1/CYP1A2 activity was investigated by ethoxyresorufin- $O$-deethylase (EROD) reaction. First, HepaRG cells were incubated for $24 \mathrm{~h}$ with the chosen test substances. $5 \mu \mathrm{M}$ 3-methylcholanthrene was used as positive control. After incubation, cells were washed with PBS and then incubated for 30 min with induction medium with $2 \mu \mathrm{M}$ ethoxyresorufin. The concentration of resorufin in the supernatant was determined by fluorescence measurement with excitation at $535 \mathrm{~nm}$ and emission at $590 \mathrm{~nm}$. Resorufin concentration was normalized to the protein content; therefore, protein content was measured using the Bicinchoninic Acid Kit for protein determination (Sigma-Aldrich, Munich, Germany).

\section{ACOX2 knockdown}

ACOX2 knockdown was performed via siRNA. $48 \mathrm{~h}$ before transfection, cells were adapted to induction medium. Cells were then transfected twice in an interval of $24 \mathrm{~h}$. A medium exchange with induction medium was performed before every transfection. Transfection procedure was done according to the manual of the transfection reagent lipofectamine RNAiMAX (catalog number: 13778150; Thermo Fisher Scientific, Waltham, MA, USA). The experimental setup included a medium control without any transfection, a control siRNA transfection (Silencer Select Negative Control 1 siRNA, catalog number: 4390844; Thermo Fisher Scientific, Waltham, MA, USA) and a transfection using a mixture of 4 different siRNAs against ACOX2 (FlexiTube GeneSolution GS8309 for ACOX2: SI0432249, SI04304258, SI00291004 and SI00290997; Qiagen, Hilden, Germany). ACOX2 knockdown was verified at the gene expression and protein levels. The established knockdown was used in combination with the AdipoRed assay. Therefore, the knockdown efficiency was checked $24 \mathrm{~h}$ after the second transfection, which was chosen as the starting time for AdipoRed assay incubation and $96 \mathrm{~h}$ after the second transfection, as the incubation time of the AdipoRed assay was set to $72 \mathrm{~h}$.

\section{Carnitin shuttle transporter assay}

The carnitine shuttle transporter assay was conducted by SOLVO (SOLVO biotechnology; a Charles River company, Budapest, Hungary) under subcontract according to a standard protocol. In brief, solubility of all substances was checked in assay buffer at $37^{\circ} \mathrm{C}$. Substances were applied up to max soluble concentration in two different assays: in an uptake transporter assay, the accumulation of the probe substrate in the presence of test substance (inhibition) and/or the accumulation of the test substance (substrate) into cells was measured. The test article, reference inhibitor and solvent control were tested 
in transporter-expressing cells in triplicates. Transporterexpressing cells were cultured according to the general SOLVO protocol (PR-CC-UPT-General Protocol for Culturing Uptake Cell Lines).

\section{Dual-luciferase reporter assay}

The assays were performed as previously described by Luckert et al. (2018). Plasmids, plasmid amount and positive controls were also used as described in the aforementioned paper. In brief, HepG2 cells were used to measure activation of NRs (AHR, CAR, FXR, GR, LXR, PPAR $\alpha$, PPAR $\gamma$, PPAR $\delta$, PXR, RAR and RXR) via dual-luciferase reporter assays. Cells were transfected $24 \mathrm{~h}$ after seeding with the plasmids for $4-6 \mathrm{~h}$ using TransIT-LT1 (Mirus Bio LCC, Madison, WI, USA). Only the AHR reporter plasmid was transfected during cell seeding as this resulted in better luciferase signals. After $4-6 \mathrm{~h}$ of transient transfection (or after $24 \mathrm{~h}$ for AHR), the cells were incubated with the chosen test compounds in culture medium containing 0.5\% DMSO. Cells were lysed with $50 \mu \mathrm{L}$ lysis buffer $(100 \mathrm{mM}$ potassium phosphate with $0.2 \%$ (v/v) Triton $\mathrm{X}-100, \mathrm{pH} 7.8) .5 \mu \mathrm{L}$ of the cell lysate was investigated. Luminescence was measured for firefly and Renilla luciferase activities in a dual luciferase assay with an Infinite M200 Pro plate reader (Tecan group, Männedorf, Switzerland), as previously described by Hampf and Gossen (2006). The firefly signal indicates an interaction with the NR, whereas the Renilla signal is used as an internal control for normalization as the plasmid is constitutively expressed by the cells.

\section{Gene expression analysis}

Incubation for gene expression analysis was performed in 12-well plate. After $24 \mathrm{~h}$ of incubation with the test substances, cells were washed twice with PBS and RNA was isolated using the RNeasy Mini Kit (Qiagen, Hilden, Germany) according to manufacturer's instructions. RNA concentration and purity were determined by Infinite M200 Pro plate reader (Tecan group, Männedorf, Switzerland) at wavelengths of $260 \mathrm{~nm}$ and $280 \mathrm{~nm}$. According to the manufacturer's instructions, $1000 \mathrm{ng}$ RNA was used for cDNA synthesis with the High Capacity cDNA Reverse Transcription Kit (Applied Biosystems, Darmstadt, Germany). Quantitative real-time RT-PCR was performed using Maxima SYBR Green/ROX qPCR Master Mix (Thermo Fisher Scientific, Waltham, MA, USA), $20 \mathrm{ng}$ cDNA, primers $(5 \mu \mathrm{M}$; see Table 1) and an AriaDx Realt-Time PCR Instrument (Agilent Technologies, Santa Clara, CA, USA). Thermal cycling conditions were used as previously described by Luckert et al. (2013). Results were evaluated using the $\Delta \Delta \mathrm{Ct}$ method (Livak and Schmittgen 2001). ACTB and GAPDH were used as reference genes as they were found to be stably expressed throughout treatments (supplementary data, Fig. S1). Their geometric mean was used for normalization.

\section{Western blotting}

For protein extraction, cells were washed with PBS and harvested with RIPA buffer (radioimmunoprecipitation assay buffer) with protease and phosphatase inhibitors. Protein extraction was performed on ice via sonication (two times for $10 \mathrm{~s}$ with $10 \%$ cycles; $25 \%$ power; Sonopuls

Table 1 Sequences of real-time RT-PCR primers

\begin{tabular}{llll}
\hline Gene & Accession number & Forward primer $\left(5^{\prime}-3^{\prime}\right)$ & Reverse primer $\left(5^{\prime}-3^{\prime}\right)$ \\
\hline$A C T B$ & ENSG00000075624 & CGTCCACCGCAAATGCTT & GTTTTCTGCGCAAGTTAGGTTTTGT \\
GAPDH & ENSG00000111640 & ATTTGGCTACAGCAACAGGG & CAACTGTGAGGAGGGGAGA \\
ACOX1 & ENSG00000161533 & CTGAAGGCTTTCACCTCCTG & GGCAGGTCGTTCAAATAGGA \\
$A C O X 2$ & ENSG00000168306 & GCTTACAGAGCCCTTTCTGGAG & AAGTCTCCAGGCCACCATTTG \\
$A H R$ & ENSG00000106546 & CCAGACCAGATTCCTCCAGA & TTCATTGCCAGAAAACCAGA \\
$C D 36$ & ENSG00000135218 & TGATGAACAGCAGCAACATTC & CAGCGTCCTGGGTTACATTT \\
$C Y P 1 A 1$ & ENSG00000140465 & ACCCTGAAGGTGACAGTTCC & TCTTGGAGGTGGCTGAGGTA \\
$C Y P 1 A 2$ & ENSG00000140505 & CTTCGCTACCTGCCTAACCC & CCCGGACACTGTTCTTGTCA \\
$C Y P 2 B 6$ & ENSG00000197408 & TTCGGCGATTCTCTGTGACC & ATGAGGGCCCCCTTGGAT \\
$C Y P 3 A 4$ & ENSG00000160868 & TCAGCCTGGTGCTCCTCTATCTAT & AAGCCCTTATGGTAGGACAAAATATTT \\
$F A S N$ & ENSG00000169710 & ACAGCGGGGAATGGGTACT & GACTGGTACAACGAGCGGAT \\
$M L X I P L$ & ENSG00000009950 & GCCTGAACAACGCCATCT & GGTCACGAAGCCACACAC \\
$N R 112(P X R)$ & ENSG00000144852 & GGCATGAAGAAGGAGATGAT & TGGGAGAAGGTAGTGTCAAA \\
$N R 113(C A R)$ & ENSG00000143257 & ATGCTGGCATGAGGAAAGAC & GTTGCACAGGTGTTTGCTGT \\
$S C D$ & ENSG00000099194 & ACCGCTGGCACATCAACTTC & CCTTGGAGACTTTCTTCCGGTC \\
$S R E B F 1$ & ENSG00000072310 & CGGAACCATCTTGGCAACAGT & CGCTTCTCAATGGCGTTGT \\
\hline
\end{tabular}


UW 2200, Bandelin Electronic GmbH \& Co. KG, Berlin, Germany). After sonication, samples were centrifuged at $4{ }^{\circ} \mathrm{C}, 20,817 \times g$ for $30 \mathrm{~min}$. The supernatant, containing the proteins, was used for protein analysis. Protein content was measured using the Bicinchoninic Acid Kit for protein determination (Sigma-Aldrich, Munich, Germany). $20 \mu \mathrm{g}$ of protein was heated to $95{ }^{\circ} \mathrm{C}$ for 5 min and separated on $10 \%$ sodium dodecylsulfate polyacrylamide gels (BioRad Mini PROTEAN Tetra System, Bio-Rad Laboratories, Inc., Hercules, CA, USA). A semi-dry method (TE 77 PWR Semi-Dry Transfer Unit, $21 \times 26 \mathrm{~cm}$; Amersham Biosciences, GE Healthcare GmbH, Solingen, Germany) was used to blot the separated proteins to nitrocellulose membranes. Membranes were blocked for $2 \mathrm{~h}$ at room temperature with $5 \%$ milk powder in Tris-buffered saline with $1 \%(\mathrm{v} / \mathrm{v})$ Tween 20 (TBST buffer). Membranes were incubated over night at $4{ }^{\circ} \mathrm{C}$ with the primary antibody against ACOX2 (1:100, in TBST with 5\% milk powder, ACOX2 (A-7): sc-514320; Santa Cruz Biotechnology, Dallas, TX, USA). The secondary antibody (Anti-mouseIgG-HRP-conjugated: A-014HRP; Seramun Diagnostica, Heidensee, Germany) was diluted 1:7500 in TBST with $5 \%$ milk powder and incubated with the membranes for $1 \mathrm{~h}$ at room temperature. As housekeeping control, pan-actin antibody (Lab Vision Actin, pan Ab-5, Mouse Monoclonal Antibody: MS-1295-P; ThermoFisher Scientific, Waltham, MA, USA) was used and diluted 1:5000 in TBST with 5\% milk powder. The housekeeping antibody was incubated for $1 \mathrm{~h}$ at room temperature with the membranes and the same secondary antibody as described before was used. Detection was done using the Super Signal West Femto Maximum Sensitivity Substrat Kit (ThermoFisher Scientific, Waltham, MA, USA) and a VersaDocTM Mp 4000 system equipped with the Quantity One Software (Vers. 4.6.1; Bio-Rad Laboratories, Inc., Hercules, CA, USA).

\section{Pesticide quantification in cell culture supernatant}

For the quantification of the test substances in cell culture supernatant, the substances were incubated with and without HepaRG cells for $8 \mathrm{~h}$ at $37{ }^{\circ} \mathrm{C}$ and $5 \% \mathrm{CO}_{2}$ in a humidified atmosphere. The incubation was performed in 12-well plates. After $8 \mathrm{~h}$, the medium was harvested and cells were washed with ultrapure water which was added to the harvested medium. Samples were diluted with ultrapure water to $21 \mathrm{~mL}$ sample volume. Measurement of DIF and FDO was performed by a certified commercial laboratory (SGS, Institute Fresenius, Berlin, Germany) according to the method laid down in DIN EN 15,662 (ASU L00.00-115). The accredited method comprises a QuEChERS solid-phase extraction method and LC-MS/ MS quantification.

\section{Measurement of CYP3A4 enzyme activity}

CYP3A4 enzyme activity was measured using the luminogenic CYP3A4 substrate Luciferin-IPA from Promega (Madison, Wisconsin, USA) (catalog number: V840A). The substrate was incubated with insect control supersomes (Corning, New York, USA) or human CYP3A4 supersomes from Corning (catalog number: 456202) (Corning, New York, USA). The latter convert the substrate to D-luciferin. Detection was performed with the luciferin detection reaction (catalog number: V859A) dissolved in reconstitution buffer with esterase (catalog number: V144A) from Promega (Madison, Wisconsin, USA). Experiments were performed in white 96-well plates in triplicates. For one well $7.35 \mu \mathrm{L}$ water, $5 \mu \mathrm{L}$ sodium phosphate buffer $(1 \mathrm{M}, \mathrm{pH} 7.4), 0.05$ $\mu \mathrm{L}$ Luciferin-IPA ( $3 \mathrm{mM}$ ), and $0.1 \mu \mathrm{L}$ CYP3A4 supersomes were mixed. Experiments were conducted by adding 12.5 $\mu \mathrm{L}$ of test compound ( $4 \times$ concentrated to compensate for the dilution effect in the assay), or a CYP3A4 inhibition control (ketoconazole, final concentration $1 \mu \mathrm{M}$ ) or water as negative control to each well. After this, $12.5 \mu \mathrm{L}$ of the mix with control supersomes as negative control or CYP3A4 supersomes was added, mixed on a plate shaker and preincubated for $10 \mathrm{~min}$ at $37^{\circ} \mathrm{C}$. The reaction was started by adding $25 \mu \mathrm{L}$ of cofactor solution, containing $33 \mathrm{mM}$ potassium chloride, $8 \mathrm{mM}$ magnesium chloride, $1 \mathrm{mM}$ NADP and $5 \mathrm{mM}$ glucose-6-phosphate. Plate was again shaken and incubated for $30 \mathrm{~min}$ at $37^{\circ} \mathrm{C}$. Finally, $50 \mu \mathrm{L}$ of luciferin detection reagent was added to each well and the plate was incubated for $20 \mathrm{~min}$ at room temperature. After this, luminescence was measured with $1 \mathrm{~s}$ integration time.

\section{Evaluation of combination effects}

The evaluation of combination effects was performed with three mathematical models: the theoretical additivity method (TA), the concentration addition concept (CA) and the independent action concept (IA). With the help of these models, a mixture effect was calculated based on the single compound effects. The calculated mixture effect refers to a dose addition assumption. Detailed description on the calculations with the different models can be found in the publication by Lasch et al. (2020a). To evaluate the combination effects, the combination index (CI) was calculated as described by Foucquier and Guedj (2015):

$\mathrm{CI}=\frac{\text { calculated mixture effect }}{\text { measured mixture effect }}$

A CI $<0.9$ indicates synergism, a CI between 0.9 and 1.1 indicates an additive effect and a CI $>1.1$ indicates antagonism (Chou 2006). Another threshold considered 

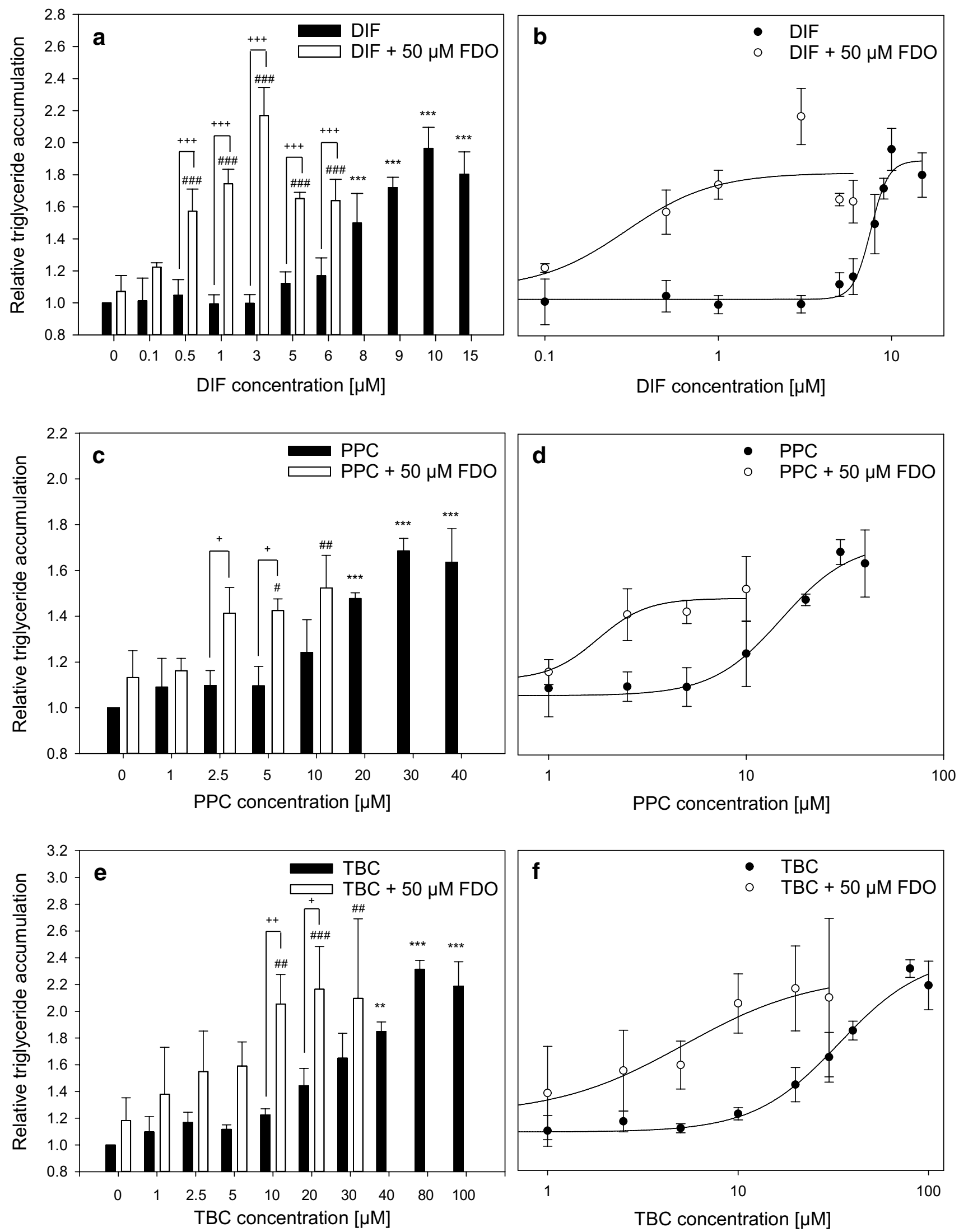
४Fig. 1 Triglyceride accumulation in HepaRG cells induced by DIF, PPC, TBC alone and their mixtures with $50 \mu \mathrm{M}$ FDO (a, c, e). Intracellular triglycerides were measured with the AdipoRed assay after $72 \mathrm{~h}$ of incubation. $\mathbf{b}, \mathbf{d}$ and $\mathbf{f}$ show the data points of DIF, PPC, TBC alone and their mixtures with $50 \mu \mathrm{M}$ FDO, respectively, and the fitted curves for $\mathrm{EC}_{50}$ calculation. Cyproconazole $(200 \mu \mathrm{M})$ was used as positive control (data not shown). Data represent mean $\pm \mathrm{SD}(\mathrm{N} \geq 3$ independent experiments). Statistic was done by one-way ANOVA with Holm-Sidak post hoc test (all pairwise): $* p \leq 0.05,{ }^{* *} p \leq 0.01$ and $* * * p \leq 0.001$ indicate significance for single compounds (black bars) against the medium control containing 0.5\% DMSO, $\# p \leq 0.05$, \#\#p $\leq 0.01$ and \#\#\#p $\leq 0.001$ indicate significance for combinations (white bars) against $0 \mu \mathrm{M}$ DIF/PPC/TBC $+50 \mu \mathrm{M}$ FDO, while $+p \leq 0.05,++p \leq 0.01$ and $+++p \leq 0.001$ indicate significance for single compounds (black bars) against combinations (white bars) at the same concentrations of DIF/PPC/TBC

to differ between additivity, antagonism and synergism is the model deviation ratio (MDR). The MDR has the same mathematical definition as the CI, but has different thresholds. An MDR $<0.5$ indicates synergism, an MDR between 0.5 and 2 indicates an additive effect and an MDR > 2 indicates antagonism (Belden et al. 2007; Cedergreen 2014).

\section{Statistics}

Statistical analysis was performed using SigmaPlot software (Version 14.0). Parametric statistical tests were chosen as they are more powerful than non-parametric tests. A one-way ANOVA followed by Dunnett 's post hoc test was performed for calculating statistical significance in a concentration series against the medium control with ${ }^{*} p \leq 0.05, * * p \leq 0.01$ and $* * * p \leq 0.001$. Scenarios with calculations of statistical differences of mixtures and single compounds were performed using one-way ANOVA followed by the Holm-Sidak post hoc test (all pairwise testing) with $* p \leq 0.05, * * p \leq 0.01$ and $* * * p \leq 0.001$ for concentration series of single compounds; ${ }^{*} p \leq 0.05,{ }^{\# \#} p \leq 0.01$ and ${ }^{\# \# \#} p \leq 0.001$ for concentration series of mixtures and $+p \leq 0.05,++p \leq 0.01$ and $+++p \leq 0.001$ for comparison of mixtures and single compounds at same concentration levels. $\mathrm{EC}_{50}$ calculation and curve fitting was also performed using SigmaPlot software (Version 14.0).

\section{Results}

\section{More than additive effects of triglyceride accumulation by mixtures}

The aim of this study was to investigate binary mixtures of steatotic and non-steatotic compounds and thus the influence of a non-steatotic compound on steatosis caused by the steatotic substance. As the tested combinations do not share the same outcome with respect liver triglyceride accumulation, we decided to analyze mixtures with increasing concentrations of the steatotic compounds and constant concentrations of the non-steatotic compound. Therefore, FDO (i.e., the non-steatotic compound) was combined at a constant concentration of $50 \mu \mathrm{M}$ with the steatotic substances DIF, PPC and TBC, which were applied at increasing concentrations. Initial analysis of cytotoxicity was performed for all test compounds and their mixtures to ensure the use of nontoxic concentrations in all experiments (data not shown). Triglyceride content of HepaRG cells was measured after $72 \mathrm{~h}$ of incubation with the chosen test compounds. Figures $1 \mathrm{a}, \mathrm{c}, \mathrm{e}$ show the induction of triglyceride accumulation of the single compounds DIF, PPC and TBC and of their mixtures with FDO. All three single steatotic substances increased the triglyceride content in HepaRG cells in a concentration-dependent manner. FDO alone did not cause a significant increase in triglyceride accumulation. The three combinations of FDO with one of the triazoles resulted in a potentiation of the steatotic effect of the single compounds. When combined with FDO, the triglyceride content of HepaRG cells increased already at low triazole concentrations, at which for the single compounds, no effect was observed. Figures $1 \mathrm{~b}, \mathrm{~d}$, f show the curves that have been used for half-maximal effective concentration $\left(\mathrm{EC}_{50}\right)$ calculation and demonstrates the shift of the curves of mixtures to the left, as compared to the curves obtained with the single compounds. The $\mathrm{EC}_{50}$ values of the single compounds and of their mixtures with FDO are listed in Table 2. All three mixtures had lower $\mathrm{EC}_{50}$ values than the respective steatotic single compounds. In summary, the results demonstrate that FDO, a compound that shows alone no effect on triglyceride accumulation, had a striking influence on this endpoint in mixtures with substances that per se cause triglyceride accumulation.

\section{Evaluation of combination effects reveals more than additive effects}

Figure 1 showed a shift of the concentration-response curve of the mixtures with FDO. To assess the combination effects, mathematical modeling with the TA, IA and CA concepts was performed. To evaluate a combination effect as additive, antagonistic or synergistic, the CI by Chou (2006) was used. All models, displayed in Fig. 2, showed a decrease in the CI value with increasing concentrations of the mixture. Especially for the TA and CA concepts according to Chou (2006), synergistic effects expressed by CI values lower than 0.9 were observed for medium and high concentration levels of the mixtures. The IA concept showed additive and slight overadditive effects. Taken together, the mathematical modeling approaches underlined the occurrence of more than 
additive effects. Supplementary Fig. S2 shows a comparison of the measured and calculated mixture effects for triglyceride accumulation.

\section{Activation of steatosis- and metabolism-relevant nuclear receptors}

As the NR activation is described as the MIE for steatosis, reporter assays for steatosis-relevant NR were performed

Table $2 \mathrm{EC}_{50}$ values $\pm \mathrm{SE}$ of the single compounds DIF, PPC and TBC and of their mixtures with $50 \mu \mathrm{M}$ FDO

\begin{tabular}{lllllll}
\hline & DIF & DIF $+50 \mu \mathrm{M}$ FDO & PPC & PPC +50 $\mu \mathrm{M}$ FDO & TBC & TBC +50 $\mu \mathrm{M} \mathrm{FDO}$ \\
\hline $\mathrm{EC}_{50}[\mu \mathrm{M}] \pm \mathrm{SE}$ & $7.6 \pm 0.36$ & $0.3 \pm 0.33$ & $15.1 \pm 3.21$ & $1.8 \pm 0.64$ & $33.8 \pm 6.13$ & $5.2 \pm 2.8$ \\
\hline
\end{tabular}

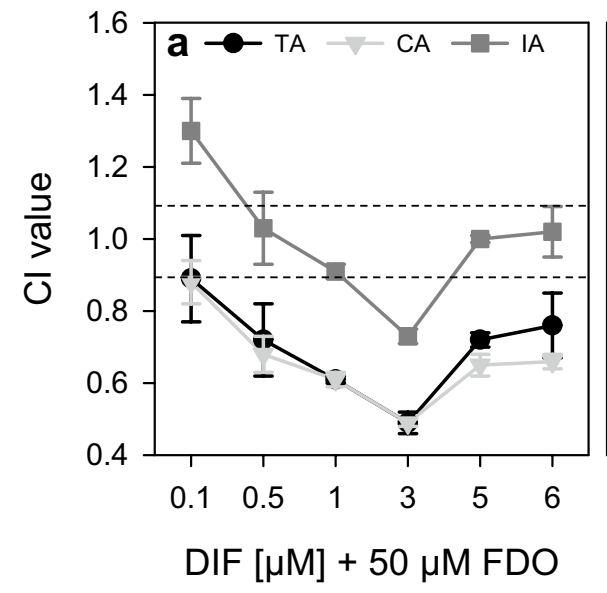

Fig. 2 Evaluation of combination effects for triglyceride accumulation caused by DIF (a), PPC (b) and TBC (c) in combination with $50 \mu \mathrm{M}$ FDO. The effects were analyzed using the TA, IA and CA concepts. CI below 0.9 indicates synergism according to Chou (2006), CI $\approx 1$ indicates dose addition, and CI above 1.1 indicates
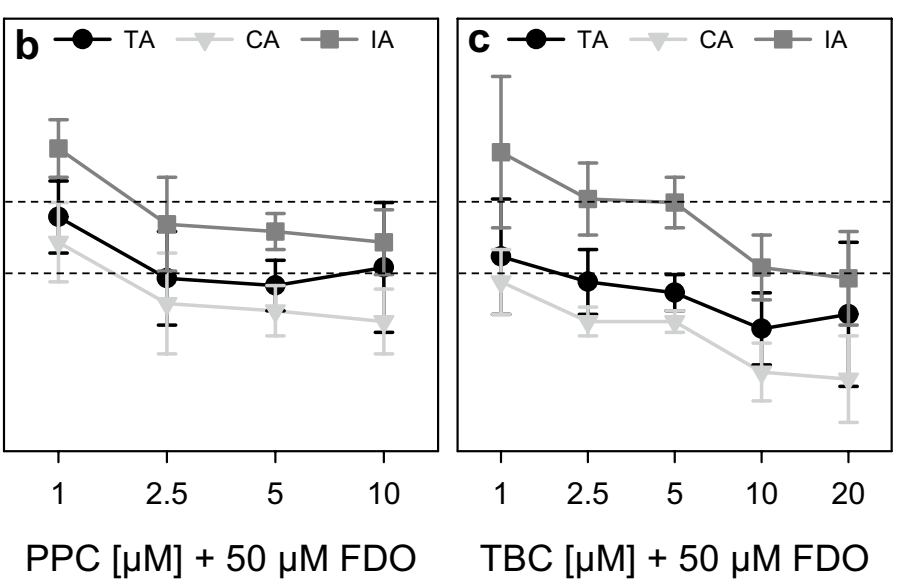

antagonism. The variation of the data is illustrated as for every biological replicate a CI value was calculated to allow the calculation of a SD of the CI values. This shows the variation of the Data represent mean $\pm \mathrm{SD}(N=3$ independent experiments).
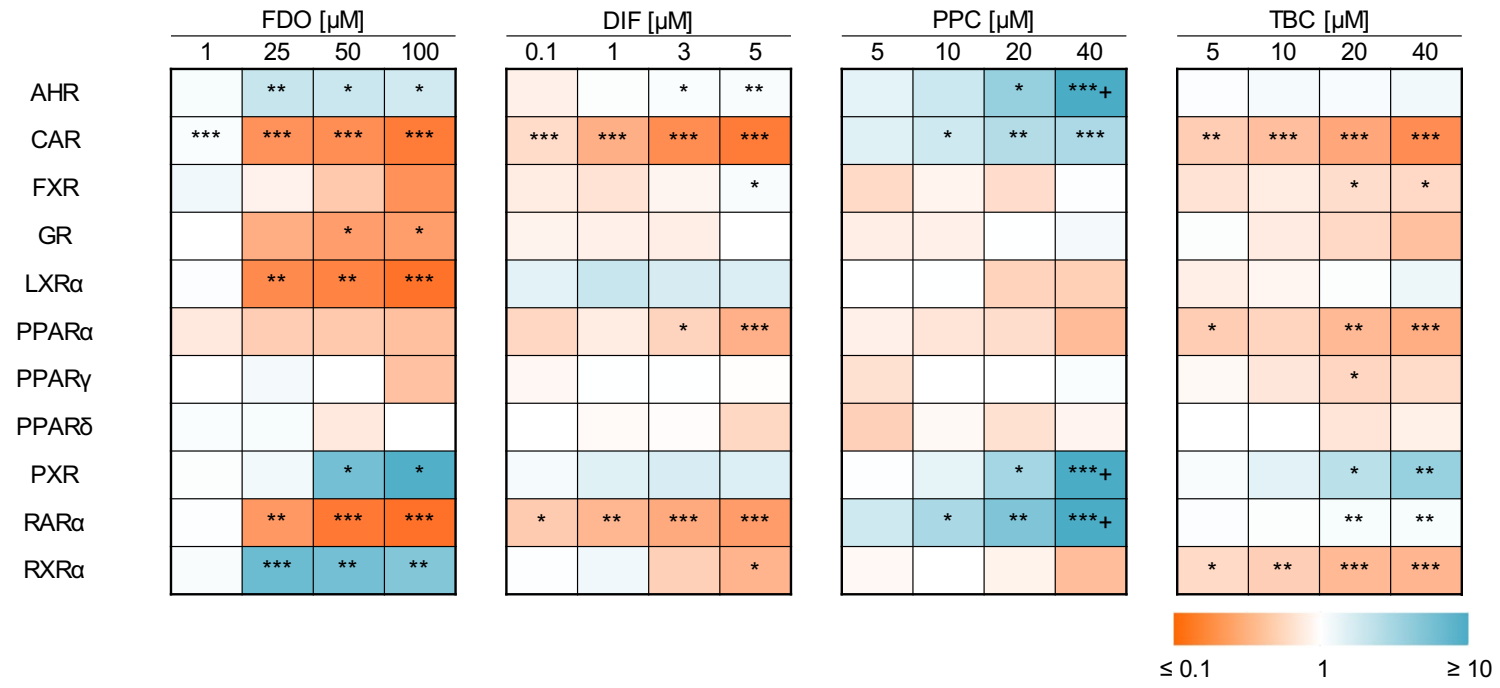

Fig. 3 Activation of steatosis-relevant NRs induced by FDO, DIF, PPC and TBC after $24 \mathrm{~h}$ incubation in HepG2 cells. Data represent mean fold changes \pm SD ( $N \geq 3$ independent experiments). Statis- tic was done by one-way ANOVA with Dunnett's test $\left({ }^{*} p \leq 0.05\right.$, ${ }^{* *} p \leq 0.01$ and $\left.{ }^{* * *} p \leq 0.001\right)$ against medium control, + indicates relative luciferase signals lower as 0.1 or higher than 10 
for the four test compounds FDO, DIF, PPC and TBC (Fig. 3) (detailed values can be found in Supplementary Data Table S1). Those results might give insight into the mode of action of the individual substances and therefore provide first explanations for the potentiation of the steatotic effect. The results revealed that all substances interacted with CAR and PXR: all compounds were agonistic at PXR, even though not statistically significant for DIF. At CAR, only PPC showed an activation, whereas FDO, DIF and TBC lead to an inhibition of the luciferase signals. Another observation was that FDO, DIF and PPC were activating AHR. Those three receptors (AHR, CAR and PXR) are especially participating in the regulation of the biotransformation of xenobiotic compounds and therefore might denote a link to metabolism as underlying cause for the observed mixture effect.

\section{Regulation of steatosis- and metabolism-related target genes}

The NR activation revealed an interaction of the test compounds with AHR, CAR and PXR. Therefore, expression changes of AHR, NRII3 (CAR) and NRII2 (PXR), their target genes CYP1A1, CYP1A2, CYP2B6 and CYP3A4, as well as some steatosis-related genes ( $A C O X 1, A C O X 2, C D 36$, FASN, MLXIPL, SCD and SREPF1) were investigated to examine if gene expression changes may be responsible for the potentiation of the steatotic effect by FDO. Figure 4 shows the altered gene expression by FDO, DIF, PPC and TBC and by the mixtures of FDO with DIF, PPC and TBC. $50 \mu \mathrm{M}$ FDO caused an upregulation of CYP1A1, CYP1A2 and $C Y P 2 B 6$, whereas NRII3 (CAR), NR1I2 (PXR), ACOX1, $A C O X 2$ and $M L X I P L$ were downregulated. As the effect on CYP1A1 and CYP1A2 expression by FDO was very high, we confirmed this result by analyzing CYP1A1/CYP1A2 activity via the EROD reaction. FDO at $50 \mu \mathrm{M}$ produced a significant increase in EROD activity which is displayed in supplementary data Fig. S3. Most of the genes regulated by FDO were also regulated by DIF, PPC and TBC. Strong combination effects of $50 \mu \mathrm{M}$ FDO with DIF, PPC or TBC were observed for NR1I3 (CAR), CYP1A1, CYP1A2, $C Y P 2 B 6$ and $A C O X 2$. These effects are illustrated in supplementary data Fig. S4. ACOX2 plays an important role in the AOP of steatosis as it is responsible for the degradation of long-branched fatty acids and a downregulation of this gene might therefore be responsible for the accumulation of triglycerides in hepatocytes.

\section{ACOX2 downregulation is not responsible for the mixture effect}

Gene expression results revealed that $50 \mu \mathrm{M}$ FDO alone and in the mixtures with DIF, PPC and TBC downregulated ACOX2 expression, while the steatotic compounds alone did not cause major changes to ACOX2 expression. ACOX2 is involved in the oxidation of branched-chain fatty acids and a decrease in ACOX2 may lead to the accumulation of branched-chain fatty acids (Baumgart et al. 1996; Ferdinandusse et al. 2018; Vanhove et al. 1993; Vilarinho et al. 2016). Therefore, we hypothesized that FDO contributed to the potentiation of steatosis in the mixtures by diminishing ACOX 2 levels, which alone might not have been sufficient to induce steatosis but in combination with the steatosispromoting molecular effects of the other compounds might have resulted in the observed mixture effects.

To investigate whether changes in ACOX2 expression are responsible for the potentiation of the steatotic effect, a knockdown of ACOX2 was performed via siRNA instead of incubating the cells with $50 \mu \mathrm{M}$ FDO. To verify the above hypothesis, such a knockdown should mimic the effects of FDO when combined with DIF, PPC or TBC. Figure 5 shows the results of the establishment of the knockdown.


Fig. 4 Gene expression analysis after $24 \mathrm{~h}$ incubation in HepaRG cells by FDO, DIF, PPC and TBC alone and by mixtures of DIF, PPC and TBC with $50 \mu \mathrm{M}$ FDO. Data represent means $\pm \mathrm{SD}(N=3$ inde- pendent experiments). Statistic was done by one-way ANOVA with Dunnett's test: $* p \leq 0.05, * p \leq 0.01$ and $* * * p \leq 0.001$ against medium control; + indicates relative expression lower as 0.1 or higher as 10 
Fig. 5 ACOX2 knockdown via siRNA. HepaRG cells were transfected twice in an interval of $24 \mathrm{~h}$ with siRNA for ACOX2 and with negative control siRNA. Relative gene expression (a) and protein amount (c) of ACOX2 were analyzed for transfected cells $24 \mathrm{~h}$ and $96 \mathrm{~h}$ after the second transfection. Relative gene expression (b) and protein amount (d) of ACOX2 were also analyzed for cells incubated for $24 \mathrm{~h}$ and $48 \mathrm{~h}$ with $50 \mu \mathrm{M}$ FDO. Data represent means $\pm \mathrm{SD}(N=3$ independent experiments). Statistic was done by one-way ANOVA with Holm-Sidak post hoc test (all pairwise), ${ }^{*} p \leq 0.05, * * p \leq 0.01$ and $* * * p \leq 0.001$
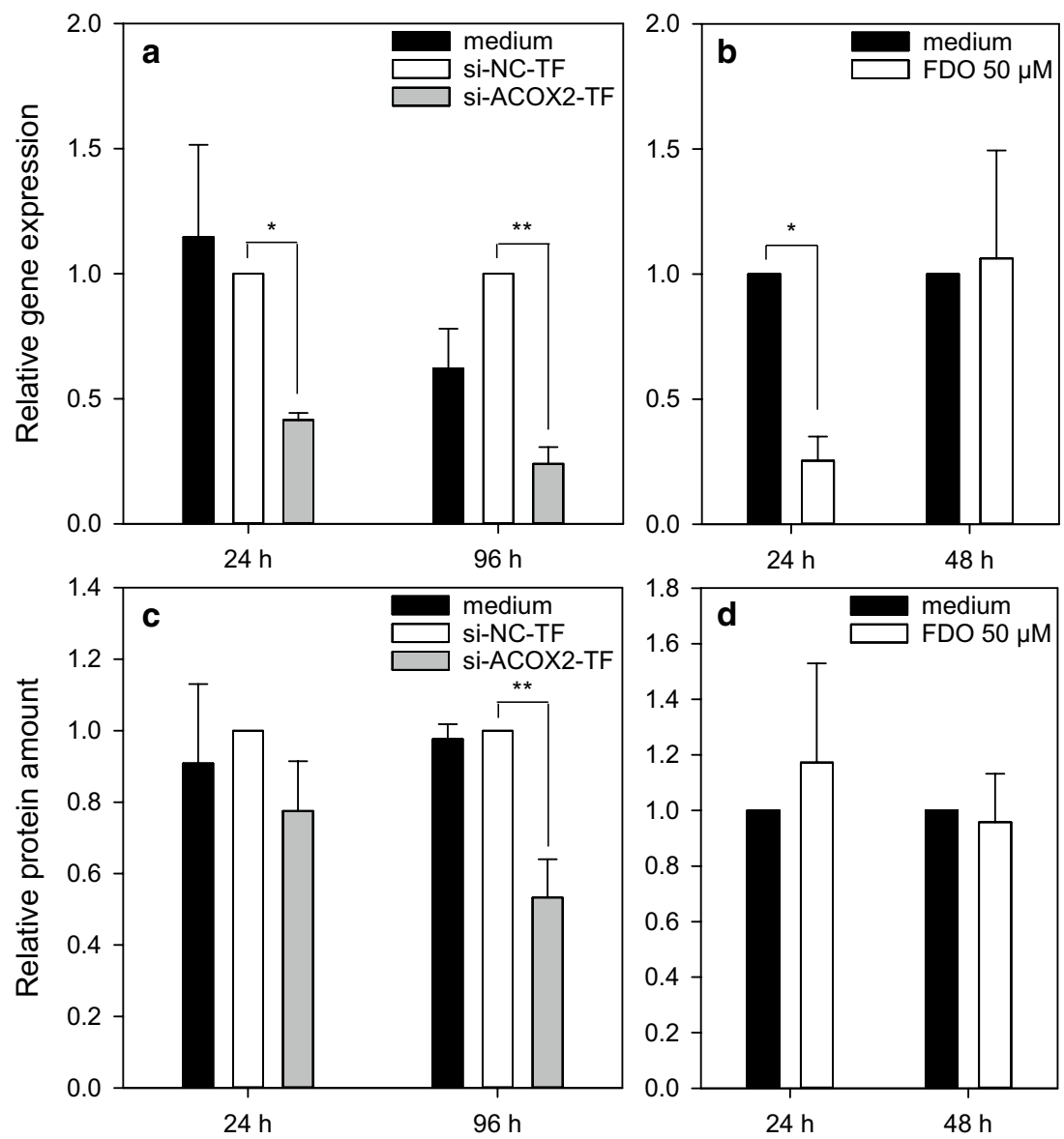

Cells were transfected twice with the siRNA and $24 \mathrm{~h}$ and $96 \mathrm{~h}$ after the second transfection, the knockdown was verified at the mRNA and protein levels, as the $24 \mathrm{~h}$ time point is the starting point of the incubation with the test substances and $96 \mathrm{~h}$ is the end of the incubation for the AdipoRed assay. The knockdown of ACOX2 mRNA already occurred after $24 \mathrm{~h}$ and was stable up to $96 \mathrm{~h}$, while the knockdown on protein level was clearly visible after $96 \mathrm{~h}$. For comparison, cells were incubated with $50 \mu \mathrm{M}$ FDO for $24 \mathrm{~h}$ and $48 \mathrm{~h}$. Here, the knockdown was only visible at the gene expression level after $24 \mathrm{~h}$, whereas at the protein level, no knockdown of ACOX2 was detected after incubation with FDO (Fig. 5). Western blot data are included in supplementary data (Fig. S5 and Table S2).

Next, HepaRG cells with a knockdown of ACOX2 were incubated with the test substance DIF for $72 \mathrm{~h}$, as the mixture of DIF and FDO had revealed the most striking mixture effects for triglyceride accumulation (cp. Fig. 1). Triglyceride accumulation was measured afterwards using the AdipoRed assay. However, triglyceride measurement did not reveal a potentiation of the steatotic effect after knockdown of $A C O X 2$ (Fig. 6). In general, it was observed that the knockdown procedure itself seemed to slightly affect the assay, as the triglyceride accumulation at same compound concentrations is lower as in non-transfected cells, irrespective of the use of $A C O X 2$-specific or negative control siRNA. No significant difference between negative control siRNA-transfected cells and ACOX2 siRNA-transfected cells was visible. In conclusion, the potentiation effect of the DIF and FDO combination on triglyceride accumulation seemed to be not related to the FDO-mediated decrease in ACOX2 expression. Another critical key player in fatty acid metabolism is the carnitine shuttle that facilitates uptake of fatty acids in mitochondria for $\beta$-oxidation (recently reviewed by Longo et al. (2016)). Since this shuttle is a transporter and some of the substances used in this work are known inhibitors of transporters (e.g. as reviewed by Gubbins and Amsden (2005)), it was reasonable to investigate if the test substances show an inhibitory effect of the carnitine shuttle. Accordingly, the carnitine shuttle was shown to be inhibited by structurally related substances like omeprazol (Pochini et al. 2009). While FDO did not show any inhibition of the carnitine shuttle up to the highest soluble concentration, DIF showed slight inhibitory effect at concentrations above $50 \mu \mathrm{M}$ (data not shown). No overadditive effect was observed, when both substances were combined in the carnitine shuttle assay. 


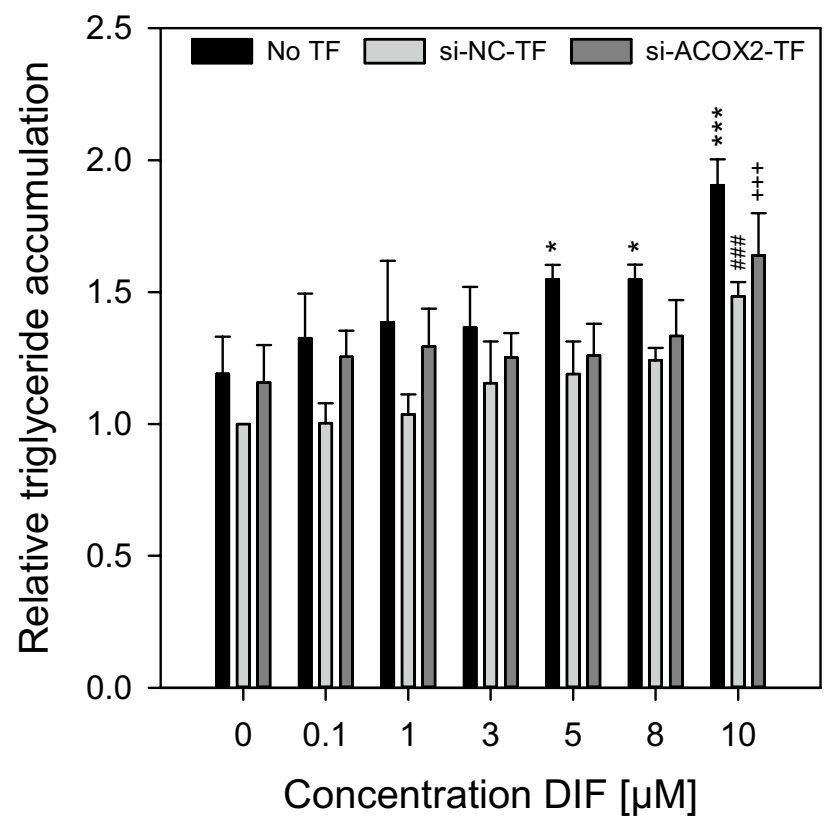

Fig. 6 Consequence of $A C O X 2$ knockdown via siRNA on triglyceride accumulation. HepaRG cells were transfected twice in an interval of $24 \mathrm{~h}$ with siRNA for $A C O X 2$, or with negative control siRNA. $24 \mathrm{~h}$ after the second transfection, $72 \mathrm{~h}$ of incubation with DIF were started and the AdipoRed assay was conducted at the end of the incubation period. Relative triglyceride level was measured. Data represent means $\pm \mathrm{SD}(\mathrm{N}=3$ independent experiments). Statistic was done by one-way ANOVA with Holm-Sidak post hoc test (all pairwise): $(* p \leq 0.05, * * p \leq 0.01$ and $* * * p \leq 0.001$ for untransfected cells (black bars) against the medium control containing $0.5 \%$ DMSO, ${ }^{\#} p \leq 0.05$, ${ }^{\# \#} p \leq 0.01$ and ${ }^{\# \# \#} p \leq 0.001$ for control siRNA-transfected cells (light gray bars) against the medium control containing 0.5\% DMSO, or $+p \leq 0.05,++p \leq 0.01$ and $+++p \leq 0.001$ for $A C O X 2$ siRNA-transfected cells (dark gray bars) against the medium control containing $0.5 \% \mathrm{DMSO}$

\section{Toxicokinetic interactions of FDO and DIF}

After having excluded ACOX2 as mediator of the observed mixture effect, the results obtained so far, showing alterations in xenobiotic-metabolizing enzymes, indicated the possibility of a toxicokinetic effect to explain the potentiation of triglyceride accumulation when cells were treated with the mixtures. Therefore, the remaining concentration of DIF was quantified in cell culture supernatant after incubation, either after cell treatment with the single substance or when applied in the mixture with FDO. The combination of DIF and FDO was chosen because it yielded the most prominent mixture effect in the AdipoRed assay. Our hypothesis was that a decrease in DIF metabolism caused by FDO could be a suitable explanation for the observed mixture effects, as a deficiency of DIF metabolism would lead to the presence of more DIF on the cells for a longer period of time in the presence of FDO as compared to single DIF treatment, thereby causing more efficient triglyceride accumulation. The results show that approximately $50 \%$ of DIF disappeared from the supernatant in the single-treatment scenario during incubation with the HepaRG cells, whereas in the mixture scenario with FDO only, around 25\% of DIF disappeared, suggesting a statistically significant inhibitory effect of FDO on the metabolism of DIF (Fig. 7a). According to literature, DIF is mainly metabolized by CYP3A4 (Wetmore et al. 2014). Therefore, we hypothesized that FDO could be an inhibitor of CYP3A4 enzyme activity. For this reason, a specific luminogenic CYP3A4 substrate was incubated with CYP3A4 supersomes alone and in combination with FDO. The transformation of the substrate was quantified via luminescence measurement. Figure $7 \mathrm{~b}$ shows a concentration-dependent decrease in CYP3A4 activity caused by FDO. This result underlined our hypothesis that FDO decreases the metabolism of DIF by inhibiting CYP3A4 enzyme activity.

\section{Discussion}

This study was designed to evaluate if combination effects on liver triglyceride accumulation may occur by mixtures of substances which do not share the same AO. For this aim, three triazoles (DIF, PPC and TBC) were selected as steatosis-inducing test compounds. Triazoles are widely used in plant protection products because of their antifungal properties (EFSA 2009). It is known that they can cause adverse effects to mammals, for example, by inhibiting CYP enzymes or via interactions with nuclear receptors followed by alterations in their target gene expression (Marx-Stoelting et al. 2020; Tully et al. 2006). The main target organ for adverse effects caused by most triazoles is the liver (Goetz and Dix 2009; Nesnow et al. 2009). FDO was chosen as nonsteatotic compound. FDO, a phenylpyrrole, belongs as well to the group of fungicides and its target organs are liver and kidney (EFSA 2007).

The AdipoRed results in HepaRG cells confirmed the classification of DIF, PPC and TBC into the CAG of hepatocellular fatty changes, and of FDO not being a member of this group of pesticides (Nielsen et al. 2012). Our study revealed a potentiation of triglyceride accumulation in HepaRG cells when the steatotic triazoles DIF, PPC and TBC were combined with the non-steatotic compound FDO. Mathematical modeling of mixture effects classified these results as more than additive. There are different approaches on how to evaluate mixture toxicity and at which CI or MDR an effect should be regarded as synergistic (Belden et al. 2007; Cedergreen 2014; Chou 2006). If a $10 \%$ deviation is assumed as proposed by Chou, our results can be described as synergistic. If an MDR of 0.5 is assumed, the observed effects are in most cases not synergistic but still more than additive. This discrepancy illustrates the need for harmonization and specific guidance in this area of increasing 


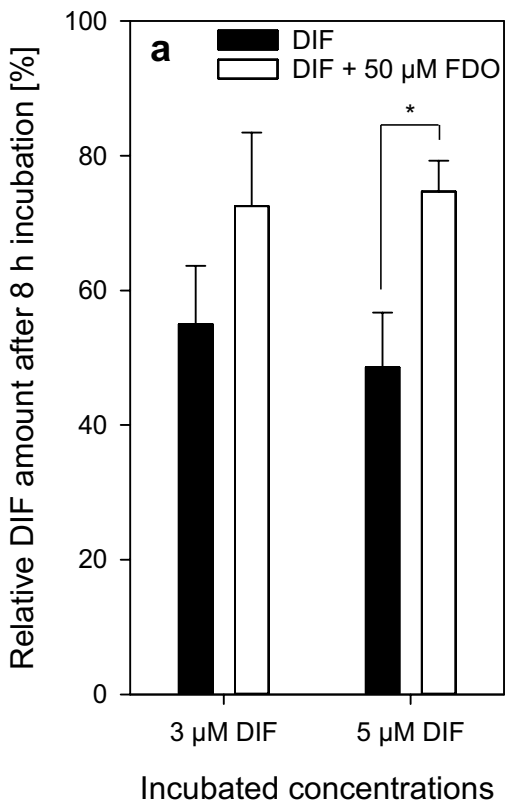

Fig.7 Analysis of toxicokinetic interactions of DIF and FDO. a Quantification of DIF in the cell culture supernatant after $8 \mathrm{~h}$ of incubation with HepaRG cells. DIF was incubated alone or in the mixture with $50 \mu \mathrm{M}$ FDO with HepaRG cells. The measured amount of DIF after incubation with HepaRG cells was normalized to the recovery of DIF from control incubations without cells. Data represent means \pm SD ( $N=3$ independent experiments). Statistics was done by one-way ANOVA with Holm-Sidak post hoc test (all pairwise) with

regulatory importance as suggested by Lasch et al. (2020b). Furthermore, it has already been shown that mixtures of FDO and triazoles can cause more than additive effects: Wang et al. (2020) showed synergistic toxic effects on mortality of embryonic zebrafish by mixtures of FDO and triadimefon, which also belongs to the group of triazoles. Moreover, it has been reported by Cedergreen (2014) that especially five groups of pesticides were involved in synergistic mixtures, for example, the group of triazoles.

An AOP-oriented in vitro testing strategy was chosen to investigate the molecular basis of the potentiation of liver triglyceride accumulation. Activation of steatosis-relevant NRs was investigated, revealing interactions of the test compounds especially with the NRs AHR, CAR and PXR. For FDO, DIF, PPC and TBC, it has already been shown that these substances can activate PXR (Chaturvedi et al. 2010; de Sousa et al. 2014; Knebel et al. 2019a; Shah et al. 2011). The results by Knebel et al. (2019a) on AHR and CAR activation by PPC and TBC are in line with our present findings. Furthermore, Shah et al. (2011) described an interaction of FDO with AHR and CAR. Gene expression analysis results confirmed the NR interaction of the test compounds, as a deregulation of CYP1A1, CYP1A2, CYP2B6 and CYP3A4, model NR target genes related to the biotransformation of
${ }^{*} p \leq 0.05$. b Investigation of CYP3A4 inhibition by FDO. LuciferinIPA, a specific CYP3A4 substrate, was incubated for $30 \mathrm{~min}$ with CYP3A4 supersomes with and without FDO or ketoconazole (KTC). KTC was used as positive control for CYP3A4 inhibition. Treatments with FDO and KTC were normalized to the control without any substance treatment. Statistics was done by one-way ANOVA with Dunnett 's test: $* * * p \leq 0.001$ against control

xenobiotic compounds, was shown. FDO upregulated the expression of several CYPs and downregulated the steatosis-related gene ACOX2. These gene expression changes were also visible for the mixtures with FDO, thus leading to hypotheses to explain the potentiation of the steatotic effect of triazoles by FDO.

The first hypothesis relates to the expression of ACOX2. ACOX2 is involved in the oxidation of branched-chain fatty acids and a decrease in ACOX2 expression may lead to the accumulation of branched-chain fatty acids, such as phytanic and pristanic acid (Baumgart et al. 1996; Ferdinandusse et al. 2018; Vanhove et al. 1993; Vilarinho et al. 2016). The steatotic compounds DIF, PPC and TBC also tended to decrease ACOX2 gene expression, but only at high compound concentrations, whereas FDO appeared to be a potent inhibitor of $A C O X 2$ expression. For this reason, $A C O X 2$ was decreased at low concentrations of DIF, PPC and TBC in the mixture experiments, constituting a possibly pro-steatotic molecular event occurring in addition to the effects caused by the triazoles. Thus, even if diminished ACOX2 levels alone, as caused by FDO treatment, are assumed to be not sufficient for steatosis induction, the combination of the molecular effects of triazoles with $A C O X 2$ inhibition by FDO might cause a more than additive effect, driven by 
toxicodynamic synergies of the different compounds. However, this hypothesis could not be confirmed based on the data obtained with the $A C O X 2$ siRNA approach.

The second hypothesis relates to toxicokinetic effects. Induction or inhibition of xenobiotic-metabolizing enzymes by one substance in the mixture can either increase or decrease the metabolism of other compounds (Hernández et al. 2017). Some triazoles are used as first-line drugs for the treatment of systemic mycoses and are therefore often prescribed in combination with other drugs. Because of their inhibitory effects on, for example, CYP3A4, drug-drug interactions are likely and might result in adverse drug reactions (Cai et al. 2020). As mentioned above, triazoles have been reported to belong to one of five groups of pesticides which are overrepresented in synergistic mixtures. Their synergistic potential is thought to be attributed to toxicokinetic effects, such as inhibition of metabolism (Cedergreen 2014). ACOX2 downregulation was shown to be not responsible for the potentiation effect on triglyceride accumulation, but our results point towards the second hypothesis dealing with a toxicokinetic effect. FDO at $50 \mu \mathrm{M}$ concentration remarkably increased the expression of different CYPs and, as a consequence, altered the cellular xenobiotic-metabolizing capacity. To the best of our knowledge, the impact of FDO on CYPIA1 and CYPIA2 expression and EROD activity has not been shown before, but it was shown by Wetmore et al. (2014) that FDO is mainly metabolized by CYP1A2. Effects of DIF, PPC and TBC on CYP1A1 and/or CYP1A2 expression or activity have been demonstrated previously (Egaas et al. 1999; Knebel et al. 2019b; Yang et al. 2018; Zhang et al. 2017). An increased metabolism of triazoles might be the underlying cause for enhanced steatotic effects, if not the parental triazole compounds, but their metabolites are the causative agents for steatosis. Up till now, however, it is not known whether the parental triazole compounds or their metabolites cause triglyceride accumulation in liver cells. The fact that NR activation by triazoles, the MIE of the steatosis AOP, was observed in HepG2 cells which are barely able to metabolize most xenobiotic compounds (including a lack of substantial expression of CYP3A4) (Luckert et al. 2017), argues for a substantial role of the non-metabolized compounds in causing steatosis. To elucidate if toxicokinetic interactions may be responsible for the potentiation effect, measurements of DIF in the supernatant of the culture medium were performed. It was observed that DIF disappeared at a slower rate from the supernatant in the presence of FDO, indicating decreased metabolism of the compound. This could be an indication for a toxicokinetic effect, as probably the metabolism or uptake of DIF is inhibited by FDO. It has been demonstrated that DIF, PPC and TBC are preferentially metabolized by CYP3A4 (Habenschus et al. 2019; Mazur and Kenneke 2008; Wetmore et al. 2014). For this reason, we investigated if FDO inhibits CYP3A4 enzyme activity. Indeed, FDO suppressed CYP3A4 enzymatic activity. This provides a mechanistic explanation for the observed diminished decrease of DIF levels when administered in mixtures, and in consequence the prolonged exposure of cells to higher concentrations of DIF can explain the phenomenon of increased triglyceride accumulation in HepaRG cells treated with a mixture of DIF and FDO.

In summary, a more than additive performance of in vitro liver triglyceride accumulation has been observed for the combination of steatosis-inducing triazole fungicides and non-steatotic compound FDO. However, future studies are necessary to confirm the relevance of the present in vitro findings in living organisms. Nonetheless, the present data clearly show that mixtures of compounds that do not share the same AO are capable of causing unexpected molecular effects. It appears that in the recent past, researchers have tended to focus on mixture effects related to toxicodynamic interactions, especially of compounds with shared $\mathrm{AO}$ and similar molecular mode(s) of action. Data from this study demonstrate that also toxicokinetic interactions have to be considered, and that the analysis of mixture effects should not be restricted to mixtures of compounds with obvious similarities of structures and toxic effects.

Supplementary Information The online version contains supplementary material available at https://doi.org/10.1007/s00204-021-02997-2.

Acknowledgements This work was supported by the German Federal Institute for Risk Assessment (Grant no. 1322-657).

Author contributions All authors contributed to the study conception and design. Material preparation, data collection and analysis were performed by AL. The first draft of the manuscript was written by AL The manuscript was edited and revised by PM-S, AB and DL. All authors read and approved the final manuscript.

Funding Open Access funding enabled and organized by Projekt DEAL. This work was supported by the German Federal Institute for Risk Assessment (Grant no. 1322-657).

\section{Compliance with ethical standards}

Conflict of interest The authors declare that they have no conflict of interest.

Open Access This article is licensed under a Creative Commons Attribution 4.0 International License, which permits use, sharing, adaptation, distribution and reproduction in any medium or format, as long as you give appropriate credit to the original author(s) and the source, provide a link to the Creative Commons licence, and indicate if changes were made. The images or other third party material in this article are included in the article's Creative Commons licence, unless indicated otherwise in a credit line to the material. If material is not included in the article's Creative Commons licence and your intended use is not permitted by statutory regulation or exceeds the permitted use, you will need to obtain permission directly from the copyright holder. To view a copy of this licence, visit http://creativecommons.org/licenses/by/4.0/. 


\section{References}

Al-Eryani L, Wahlang B, Falkner KC, Guardiola JJ, Clair HB, Prough RA, Cave M (2015) Identification of environmental chemicals associated with the development of toxicant-associated fatty liver disease in rodents. Toxicol Pathol 43:482-497. https://doi. org/10.1177/0192623314549960

Ankley GT et al (2010) Adverse outcome pathways: a conceptual framework to support ecotoxicology research and risk assessment. Environ Toxicol Chem 29:730-741. https://doi.org/10.1002/etc.34

Antherieu $S$ et al (2010) Stable expression, activity, and inducibility of cytochromes P450 in differentiated HepaRG cells. Drug Metab Dispos 38:516-525. https://doi.org/10.1124/dmd.109.030197

Baumgart E et al (1996) Molecular characterization of the human peroxisomal branched-chain acyl-CoA oxidase: cDNA cloning, chromosomal assignment, tissue distribution, and evidence for the absence of the protein in Zellweger syndrome. Proc Natl Acad Sci USA 93:13748-13753. https://doi.org/10.1073/pnas.93.24.13748

Belden JB, Gilliom RJ, Lydy MJ (2007) How well can we predict the toxicity of pesticide mixtures to aquatic life? Integr Environ Assess Manag Int J 3:364-372

Cai T, Liao Y, Chen Z, Zhu Y, Qiu X (2020) the influence of different triazole antifungal agents on the pharmacokinetics of cyclophosphamide. Ann Pharmacother 54:676-683. https://doi. org/10.1177/1060028019896894

Cedergreen N (2014) Quantifying synergy: a systematic review of mixture toxicity studies within environmental toxicology. PLoS ONE 9:e96580. https://doi.org/10.1371/journal.pone.0096580

Chaturvedi NK, Kumar S, Negi S, Tyagi RK (2010) Endocrine disruptors provoke differential modulatory responses on androgen receptor and pregnane and xenobiotic receptor: potential implications in metabolic disorders. Mol Cell Biochem 345:291-308. https:// doi.org/10.1007/s11010-010-0583-6

Chou TC (2006) Theoretical basis, experimental design, and computerized simulation of synergism and antagonism in drug combination studies. Pharmacol Rev 58:621-681. https://doi.org/10.1124/ pr.58.3.10

de Sousa G, Nawaz A, Cravedi JP, Rahmani R (2014) A concentration addition model to assess activation of the pregnane $\mathrm{X}$ receptor (PXR) by pesticide mixtures found in the French diet. Toxicol Sci 141:234-243. https://doi.org/10.1093/toxsci/kfu120

ECHA (2017) Guidance on the Biocidal Products Regulation European Chemicals Agancy Volume III Human Health, Assessment \& Evaluation (Parts b+C) doi: https://doi.org/10.2823/143042

EFSA (2007) Conclusion regarding the peer review of the pesticide risk assessment of the active substance fludioxonil. EFSA J 5:110r. https://doi.org/10.2903/j.efsa.2007.110r

EFSA (2009) Scientific opinion on risk assessment for a selected group of pesticides from the triazole group to test possible methodologies to assess cumulative effects from exposure through food from these pesticides on human health. EFSA J 7:1167. https:// doi.org/10.2903/j.efsa.2009.1167

Egaas E, Sandvik M, Fjeld E, Källqvist T, Goksøyr A, Svensen A (1999) Some effects of the fungicide propiconazole on cytochrome P450 and glutathione S-transferase in brown trout (Salmo trutta). Comp Biochem Physiol Part C Pharmacol Toxicol Endocrinol 122:337-344. https://doi.org/10.1016/S0742-8413(98)10133-0

Ferdinandusse $\mathrm{S}$ et al (2018) A novel case of ACOX2 deficiency leads to recognition of a third human peroxisomal acyl-CoA oxidase. Biochim Biophys Acta (BBA) Mol Basis Dis 1864:952-958. https ://doi.org/10.1016/j.bbadis.2017.12.032

Foucquier J, Guedj M (2015) Analysis of drug combinations: current methodological landscape. Pharmacol Res Perspect 3:e00149e00149. https://doi.org/10.1002/prp2.149
Fromenty B, Pessayre D (1997) Impaired mitochondrial function in microvesicular steatosis effects of drugs, ethanol, hormones and cytokines. J Hepatol 26:43-53. https://doi.org/10.1016/S0168 -8278(97)80496-5

Goetz AK, Dix DJ (2009) Mode of action for reproductive and hepatic toxicity inferred from a genomic study of triazole antifungals. Toxicol Sci 110:449-462. https://doi.org/10.1093/toxsci/kfp098

Gripon P et al (2002) Infection of a human hepatoma cell line by hepatitis B virus. Proc Natl Acad Sci USA 99:15655-15660. https:// doi.org/10.1073/pnas.232137699

Gubbins PO, Amsden JR (2005) Drug-drug interactions of antifungal agents and implications for patient care. Expert Opin Pharmacother 6:2231-2243. https://doi.org/10.1517/14656566.6.13.2231

Habenschus MD, Nardini V, Dias LG, Rocha BA, Barbosa F, de Oliveira ARM (2019) vitro enantioselective study of the toxicokinetic effects of chiral fungicide tebuconazole in human liver microsomes. Ecotoxicol Environ Saf 181:96-105. https://doi. org/10.1016/j.ecoenv.2019.05.071

Hampf M, Gossen M (2006) A protocol for combined Photinus and Renilla luciferase quantification compatible with protein assays. Anal Biochem 356:94-99. https://doi.org/10.1016/j. ab.2006.04.046

Hernández AF, Gil F, Lacasaña M (2017) Toxicological interactions of pesticide mixtures: an update. Arch Toxicol 91:3211-3223. https ://doi.org/10.1007/s00204-017-2043-5

Joshi-Barve S, Kirpich I, Cave MC, Marsano LS, McClain CJ (2015) Alcoholic, nonalcoholic, and toxicant-associated steatohepatitis: mechanistic similarities and differences cellular and molecular. Gastroenterol Hepatol 1:356-367. https://doi.org/10.1016/j.jcmgh 2015.05.006

Knebel C, Buhrke T, Sussmuth R, Lampen A, Marx-Stoelting P, Braeuning A (2019a) Pregnane X receptor mediates steatotic effects of propiconazole and tebuconazole in human liver cell lines. Arch Toxicol 93:1311-1322. https://doi.org/10.1007/s00204-01902445-2

Knebel C, Heise T, Zanger UM, Lampen A, Marx-Stoelting P, Braeuning A (2019b) The azole fungicide tebuconazole affects human CYP1A1 and CYP1A2 expression by an aryl hydrocarbon receptor-dependent pathway. Food Chem Toxicol 123:481-491. https ://doi.org/10.1016/j.fct.2018.11.039

Lasch A, Lichtenstein D, Marx-Stoelting P, Braeuning A, Alarcan J (2020b) Mixture effects of chemicals: the difficulty to choose appropriate mathematical models for appropriate conclusions. Environ Pollut 260:113953. https://doi.org/10.1016/j.envpo 1.2020 .113953

Lasch A, Alarcan J, Lampen A, Braeuning A, Lichtenstein D (2020a) Combinations of LXR and RXR agonists induce triglyceride accumulation in human HepaRG cells in a synergistic manner. Arch Toxicol. https://doi.org/10.1007/s00204-020-02685-7

Livak KJ, Schmittgen TD (2001) Analysis of relative gene expression data using real-time quantitative per and the $2-\Delta \Delta \mathrm{CT}$ method. Methods 25:402-408. https://doi.org/10.1006/meth.2001.1262

Longo N, Frigeni M, Pasquali M (2016) Carnitine transport and fatty acid oxidation. Biochem Biophys Acta 1863:2422-2435. https:// doi.org/10.1016/j.bbamcr.2016.01.023

Luckert C, Ehlers A, Buhrke T, Seidel A, Lampen A, Hessel S (2013) Polycyclic aromatic hydrocarbons stimulate human CYP3A4 promoter activity via PXR. Toxicol Lett 222:180-188

Luckert $\mathrm{C}$ et al (2017) Comparative analysis of 3D culture methods on human HepG2 cells. Arch Toxicol 91:393-406. https://doi. org/10.1007/s00204-016-1677-z

Luckert $C$ et al (2018) Adverse outcome pathway-driven analysis of liver steatosis in vitro: a case study with cyproconazole. Chem Res Toxicol 31:784-798. https://doi.org/10.1021/acs.chemrestox .8b00112 
Marx-Stoelting P, Knebel C, Braeuning A (2020) The connection of Azole fungicides with xeno-sensing nuclear receptors. Drug Metab Hepat Cells. https://doi.org/10.3390/cells9051192

Mazur CS, Kenneke JF (2008) Cross-species comparison of conazole fungicide metabolites using rat and rainbow trout (Onchorhynchus mykiss) hepatic microsomes and purified human CYP 3A4. Environ Sci Technology 42:947-954. https://doi.org/10.1021/ es072049b

Mellor CL, Steinmetz FP, Cronin MT (2016) The identification of nuclear receptors associated with hepatic steatosis to develop and extend adverse outcome pathways. Crit Rev Toxicol 46:138-152. https://doi.org/10.3109/10408444.2015.1089471

More SJ et al (2019) Guidance on harmonised methodologies for human health, animal health and ecological risk assessment of combined exposure to multiple chemicals. EFSA J 17:e05634. https://doi.org/10.2903/j.efsa.2019.5634

Nesnow S, Ward W, Moore T, Ren H, Hester SD (2009) Discrimination of tumorigenic triazole conazoles from phenobarbital by transcriptional analyses of mouse liver gene expression. Toxicology Sci 110:68-83. https://doi.org/10.1093/toxsci/kfp076

Nielsen E et al (2012) Identification of cumulative assessment groups of pesticides. EFSA Support Publ 9:269E. https://doi.org/10.2903/ sp.efsa.2012.EN-269

OECD (2018) Consideration for assessing the risks of combined exposure to multiple chemicals environment, Health and Sfety Division, Environment Directorate Series on Testing and Assessment No. 296

Perumpail BJ, Khan MA, Yoo ER, Cholankeril G, Kim D, Ahmed A (2017) Clinical epidemiology and disease burden of nonalcoholic fatty liver disease. World J Gastroenterol 23:8263-8276. https:// doi.org/10.3748/wjg.v23.i47.8263

Pochini L, Scalise M, Indiveri C (2009) Inactivation by omeprazole of the carnitine transporter (OCTN2) reconstituted in liposomes. Chem Biol Interact 179:394-401. https://doi.org/10.1016/j. cbi.2008.10.052

Rotter S et al (2018) Overview on legislation and scientific approaches for risk assessment of combined exposure to multiple chemicals: the potential EuroMix contribution. Crit Rev Toxicol 48:796-814. https://doi.org/10.1080/10408444.2018.1541964

Shah I et al (2011) Using nuclear receptor activity to stratify hepatocarcinogens. PLoS ONE 6:e14584. https://doi.org/10.1371/journ al.pone. 0014584

Tanner N et al (2018) Regulation of drug metabolism by the interplay of inflammatory signaling steatosis, and xeno-sensing receptors in HepaRG cells. Drug Metab Dispos 46:326-335. https://doi. org/10.1124/dmd.117.078675
Tolosa L, Gomez-Lechon MJ, Jimenez N, Hervas D, Jover R, Donato MT (2016) Advantageous use of HepaRG cells for the screening and mechanistic study of drug-induced steatosis. Toxicol Appl Pharmacol 302:1-9. https://doi.org/10.1016/j.taap.2016.04.007

Tully DB et al (2006) Gene expression profiling in liver and testis of rats to characterize the toxicity of triazole fungicides. Toxicol Appl Pharmacol 215:260-273. https://doi.org/10.1016/j. taap.2006.02.015

Vanhove GF, Van Veldhoven PP, Fransen M, Denis S, Eyssen HJ, Wanders RJ, Mannaerts GP (1993) The CoA esters of 2-methylbranched chain fatty acids and of the bile acid intermediates di- and trihydroxycoprostanic acids are oxidized by one single peroxisomal branched chain acyl-CoA oxidase in human liver and kidney. J Biol Chem 268:10335-10344

Vilarinho S et al (2016) ACOX2 deficiency: a disorder of bile acid synthesis with transaminase elevation, liver fibrosis, ataxia, and cognitive impairment. Proc Natl Acad Sci USA 113:11289-11293. https://doi.org/10.1073/pnas.1613228113

Villeneuve DL et al (2014) Adverse outcome pathway (AOP) development I: strategies and principles. Toxicol Sci 142:312-320. https ://doi.org/10.1093/toxsci/kfu199

Vinken M (2015) Adverse outcome pathways and drug-induced liver injury testing. Chem Res Toxicol 28:1391-1397. https://doi. org/10.1021/acs.chemrestox.5b00208

Wang Y et al (2020) Combined toxic effects of fludioxonil and triadimefon on embryonic development of zebrafish (Danio rerio). Environ Pollut 260:114105. https://doi.org/10.1016/j.envpo 1.2020 .114105

Wetmore BA et al (2014) Incorporating population variability and susceptible subpopulations into dosimetry for high-throughput toxicity testing. Toxicol Sci 142:210-224. https://doi.org/10.1093/ toxsci/kfu169

Yang JD, Liu SH, Liao MH, Chen RM, Liu PY, Ueng TH (2018) Effects of tebuconazole on cytochrome P450 enzymes, oxidative stress, and endocrine disruption in male rats. Environ Toxicol. https://doi.org/10.1002/tox.22575

Zhang L, Dong X, Wang C, Zuo Z, Chen M (2017) Bioaccumulation and the expression of hepatic cytochrome $\mathrm{P} 450$ genes in marine medaka (Oryzias melastigma) exposed to difenoconazole. J Environ Sci 52:98-104. https://doi.org/10.1016/j.jes.2016.03.011

Publisher's Note Springer Nature remains neutral with regard to jurisdictional claims in published maps and institutional affiliations. 